\title{
Modul Digitalisasi Mikroskop
}

\author{
Masyhud Muqoddam *1, Wisnu Kartika ${ }^{2}$, Susilo Ari Wibowo ${ }^{3}$ \\ ${ }^{1,2}$ Universitas Muhammadiyah Yogyakarta, Indonesia \\ ${ }^{3}$ Rumah Sakit Islam Klaten, Indonesia
}

\section{INFO ARTIKEL}

\section{Alamat Web Artikel:}

https://journal.umy.ac.id/index.php /mt/article/view/7257

DOI:

https://doi.org/10.18196/mt.020113

\section{Data Artikel:}

Diterima:

21 Oktober 2019

Direview:

13 November 2019

Direvisi:

10 Desember 2019

Disetujui:

07 April 2020

\section{Korespondensi:}

masyhud.muqoddam.2016@vokasi. umy.ac.id

\begin{abstract}
ABSTRAK
Mikroskop merupakan alat yang sering digunakan pada Laboratorium Rumah Sakit untuk mengamati benda kecil berukuran mikro. Pada era digital saat ini masih banyak penggunaan mikroskop konvensional di Rumah Sakit Nasional, sehingga penggunaannya menjadi kurang efektif. Pemanfaatan digitalisasi mikroskop sangat dibutuhkan supaya dapat mengikuti perubahan zaman. Penelitian ini bertujuan membuat modul digitalisasi mikroskop yang dapat mempermudah pekerjaan analis kesehatan di Laboratorium. Perancangan prototype dengan menggunakan Raspberry Pi Camera. Modul Raspberry Pi Camera akan mengubah data analog dari mikroskop menjadi data digital berupa citra gambar yang diproses oleh Raspberry $P i$ kemudian akan ditampilkan pada layar LCD. Fitur Freeze juga terdapat pada alat tersebut. Hasil data citra berupa gambar dapat disimpan dalam sebuah media penyimpanan seperti flashdisk untuk keperluan arsip dan analisis tingkat lanjut. Hasil survei kinerja modul digitalisasi mikroskop ini di Laboratorium Rumah Sakit Islam Klaten menunjukkan bahwa seluruh responden setuju terhadap semua aspek penilaian kinerja modul dengan jangkauan rata-rata presentase sebesar $60 \%-79.99 \%$.
\end{abstract}

Kata Kunci: Mikroskop, Qt Creator, Raspberry pi, Raspberry pi Kamera

\begin{abstract}
A microscope is a tool usually used in many hospital laboratories to observe small micro-sized objects. In the digital era, there are still many conventional microscopes in National Hospitals, leading to its less effective use. The microscope digitization is necessary to keep up with the ever-changing times. This study aimed to create a microscope digitization module to facilitate the work of health analysts in the laboratory. The prototype was designed by using the Raspberry Pi Camera. The Raspberry Pi Camera module will convert analog data from the microscope into digital data in the form of images processed by the Raspberry $\mathrm{Pi}$ and displayed on the LCD screen. Also, the Freeze feature is available. The results were in the form of images and stored in a storage medium such as a flash disk for archival purposes and advanced analysis. The results of the survey on the performance of this microscope digitization module at the Klaten Islamic Hospital Laboratory showed that all respondents agreed with all aspects of the module performance appraisal with an average range of $60 \%-79.99 \%$.
\end{abstract}

Keywords: Microscope, Qt Creator, Raspberry pi, Raspberry pi Camera

\section{PENDAHULUAN}

Mikroskop merupakan peralatan yang sering digunakan di Laboratorium dan berfungsi untuk mengamati suatu objek yang sangat kecil dengan cara melakukan perbesaran bayangan objek dengan menggunakan lensa. Mikroskop memiliki dua kali proses perbesaran yaitu pada lensa objektif (lensa yang dekat dengan objek) dan lensa okuler (lensa yang dekat dengan mata) [1]. Mikroskop memiliki banyak macam jenis. Terdapat dua tipe mikroskop yang saat ini sering digunakan yaitu mikroskop monokular (dengan 1 lensa okuler) dan mikroskop binokular (dengan sepasang lensa okuler). Perkembangan teknologi pada mikroskop saat ini sudah sampai pada mikroskop digital yang merupakan pengembangan dari mikroskop konvensional biasa, mikroskop 


\section{Muqoddam, Kartika, Wibowo \\ Modul Digitalisasi Mikroskop}

digital yaitu mikroskop yang memungkinkan gambar untuk ditampilkan pada layar monitor dan data gambar dapat disimpan sebagai arsip dan analisis tingkat lanjut [2].

Penggunaan mikroskop binokular konvensional masih banyak digunakan khususnya di Laboratorium Rumah Sakit Nasional. Pekerjaan di Laboratorium akan mudah dan efektif apabila menggunakan mikroskop digital yang telah dilengkapi teknologi modern tersebut [3], akan tetapi harga dari mikroskop digital cukup mahal dibandingkan dengan mikroskop konvensional yang masih banyak digunakan di Laboratorium Rumah Sakit. Untuk mengurangi biaya pengeluaran, daripada mengganti mikroskop biologi konvensional ke mikroskop digital maka pada penelitian ini dilakukan perancangan sebuah alat yang digunakan untuk mengubah data analog menjadi data digital berupa citra (gambar) dari mikroskop menggunakan sensor kamera [4] dan ditampilkan pada layar monitor yang dapat digunakan pada mikroskop biologi kovensional.

\section{METODE PENELITIAN}

Pada bagian ini dijelaskan metode yang digunakan dan diagram alirnya. Metode yang dilakukan dalam penelitian ini terdiri dari beberapa tahap, yaitu: perancangan hardware, perancangan software, pengujian alat, dan pengambilan data.

\subsection{Perancangan Hardware}

Perancangan hardware pada modul penelitian ini menggunakan beberapa komponen diantaranya Raspberry Pi 3, Raspberry Pi Camera, dan layar LCD (Liquid Crystal Display), Sedangkan perangkat lunak yang digunakan adalah software $Q t$ Creator sebagai pengolah data dari sensor kamera, tampilan pada layar serta fitur-fitur lainnya. Raspberry Pi Camera yang digunakan adalah tipe OV5647 yang memiliki resolusi 5 Megapixel. Pada Gambar 1 merupakan penjelasan dari diagram blok sistem.

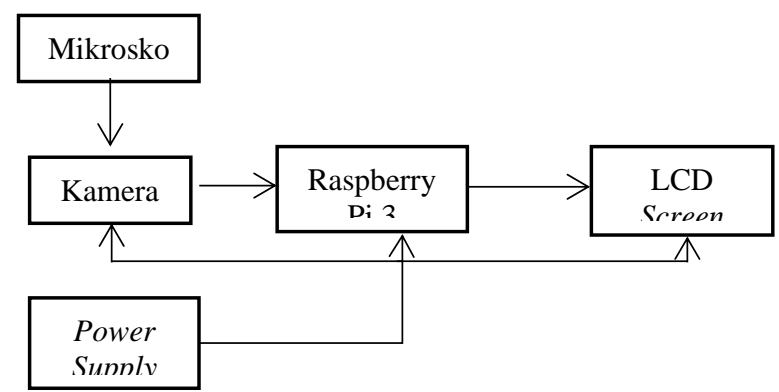

Gambar 1. Blok Diagram Sistem

Power supply akan memberikan daya listrik yang dibutuhkan untuk Rasberry Pi 3, kamera, dan $L C D$ Screen. Kamera akan menangkap dan merekam bayangan objek yang telah diperbesar oleh lensa objektif dan okuler pada mikroskop tersebut kemudian data yang telah direkam oleh kamera diproses oleh Raspberry Pi. Hasil data yang telah diproses akan ditampilkan pada layar LCD sehingga dapat terlihat dengan jelas objek yang sedang diamati. Pada Gambar 2 merupakan desain modul penelitian yang sudah selesai dibuat.

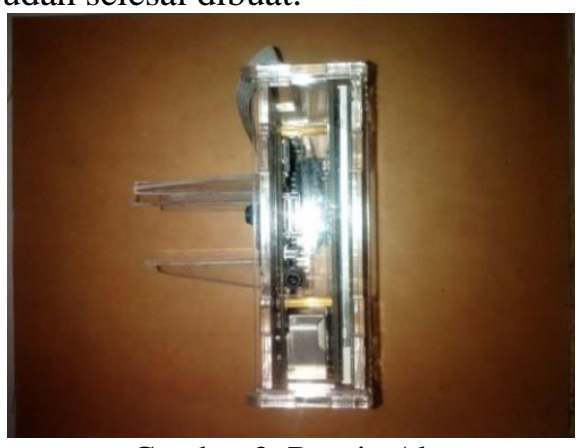

Gambar 2. Desain Alat 


\section{Muqoddam, Kartika, Wibowo \\ Modul Digitalisasi Mikroskop}

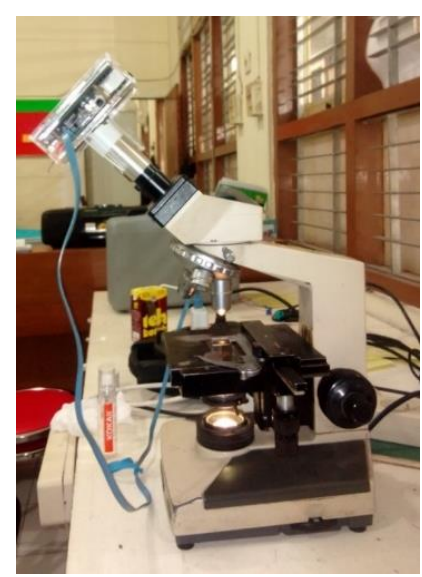

Gambar 3. Penempatan Modul pada Mikroskop

Dari beberapa komponen kemudian dirangkai dan dilengkapi casing pada bagian luarnya agar komponen yang ada didalamnya terlindungi. Pada Gambar 3 merupakan penempatan modul pada mikroskop dan modul telah siap untuk digunakan.

\subsection{Perancangan Software}

Perangkat lunak pada modul ini digunakan sebagai pengolah data dari sensor kamera dan merancang sebuah aplikasi yang berbasis UI (User Interface) untuk menampilkan gambar yang direkam oleh kamera dan beberapa fitur lainnya. Pada Gambar 4 merupakan diagram alir dari pemrograman perangkat lunak.

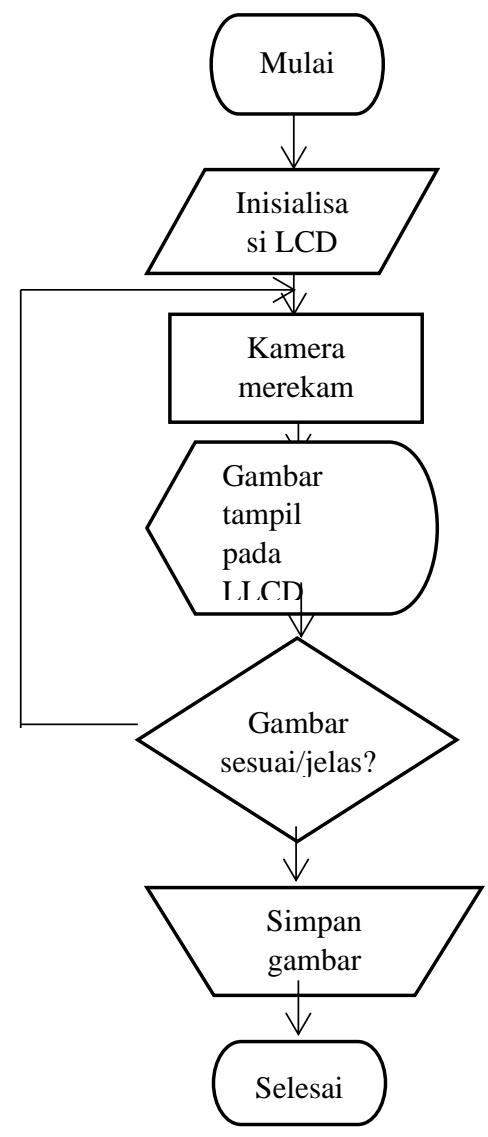

Gambar 4. Diagram Alir Program

Penjelasan diagram alir pada Gambar 4 ketika kondisi mulai pada diagram berarti modul dinyalakan dengan menghubungkan modul dengan catu daya. Kemudian dilakukan proses

Medika Teknika : Jurnal Teknik Elektromedik Indonesia, Vol 02 No. 1, Oktober $2020 \mid 21$ 


\section{Muqoddam, Kartika, Wibowo \\ Modul Digitalisasi Mikroskop}

inisialisasi LCD pada modul, pada proses ini LCD akan menampilkan program yang sedang berjalan pada modul. Setelah proses pemuatan program, maka kamera akan memulai proses perekaman objek yang berada di depan kamera tersebut sehingga gambar tersebut ditampilkan pada layar LCD. Gambar yang ditampilkan dapat berupa gambar jelas dan gambar tidak jelas. Ketika gambar yang ditangkap tidak jelas maka kamera akan melakukan perekaman kembali sehingga gambar dapat terlihat jelas. Gambar yang terlihat jelas dapat disimpan dengan menekan tombol Capture yang ada pada layar LCD.

\subsection{Teknik Pengambilan Data}

Pengambilan data dilakukan dengan dua cara yaitu pengujian menggunakan sampel (air sumur dan dahak) dan pengujian survei kinerja modul oleh responden pekerja Laboratorium di Rumah Sakit. Sampel data diperoleh dari kuisioner kinerja modul yang akan diisi oleh responden yaitu petugas yang ada di laboratorium. Petugas akan dipandu dalam penggunaan modul untuk melakukan pengamatan terhadap penggunaan alat. Sehingga data kuisioner digunakan untuk analisis kinerja modul tersebut [5].

Metode yang digunakan untuk menganalisis data menggunakan metode skala Likert. Skala yang digunakan untuk pengukuran kinerja modul ada 5 pilihan yaitu sangat tidak setuju (STS), tidak setuju (TS), cukup (C), setuju (S), dan sangat setuju (SS). Dari skala tersebut memiliki bobot nilai tersendiri. Bobot nilai digunakan untuk mengukur tingkat persepsi dari masing - masing responden terhadap pertanyaan yang diajukan. Kemudian dari jumlah bobot nilai tersebut dikalkulasikan sehingga dapat menghasilkan nilai persentase [6]. Untuk persentase dan bobot nilai ditampilkan pada Tabel 1.

Tabel 1. Bobot dan Persentase Nilai

\begin{tabular}{|l|l|l|l|}
\hline \multicolumn{2}{|c|}{ Bobot Nilai } & \multicolumn{2}{c|}{ Persentase Nilai } \\
\hline STS & 1 & $0 \%-19.99 \%$ & STS \\
\hline TS & 2 & $20 \%-39.99 \%$ & TS \\
\hline C & 3 & $40 \%-59.99 \%$ & C \\
\hline S & 4 & $60 \%-79.99 \%$ & S \\
\hline SS & 5 & $80 \%-100 \%$ & SS \\
\hline
\end{tabular}

Data yang telah diambil kemudian akan dihitung jumlah total skor untuk mendapatkan hasil interpretasi. Total skor didapatkan dengan cara mengkalikan setiap poin jawaban dengan bobot nilai. Untuk penilaian interpretasi dihasilkan dengan menggunakan rumus indeks $\%$ pada Persamaan 2-1.

Indeks $\%=$ Total skor $/$ Skor maksimum x 100\%

Skor maksimum yaitu jumlah responden dikali bobot nilai tertinggi.

\section{HASIL DAN PEMBAHASAN}

Berdasarkan pengujian yang dilakukan didapatkan hasil sebagai berikut.

\subsection{Pengujian Menggunakan Sample Air Sumur dan Dahak}

Pengujian sampel air sumur hanya dapat dilakukan dengan perbesaran 40 kali dan 100 kali. Pada Gambar 5 dan Gambar 6 merupakan hasil dari pengujian tersebut. 
Muqoddam, Kartika, Wibowo

Modul Digitalisasi Mikroskop

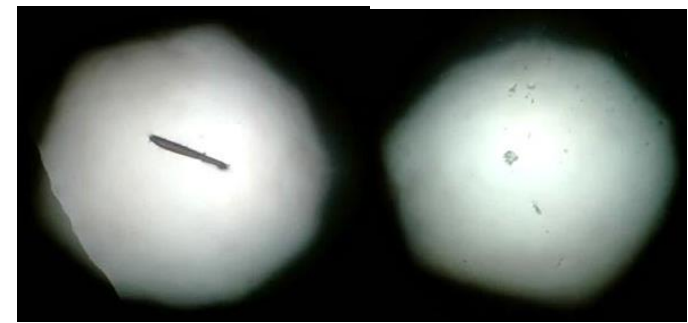

Gambar 5. Sampel Air Sumur Pada Perbesaran 40 kali

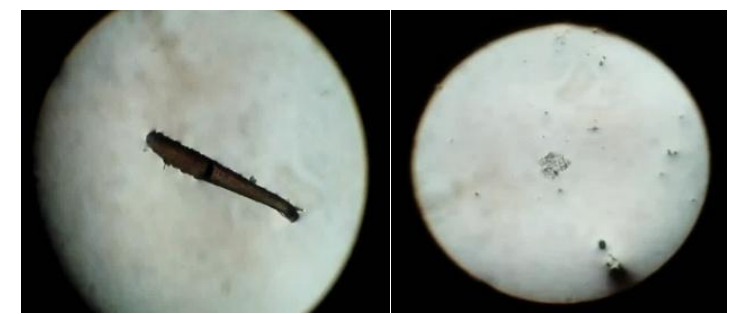

Gambar 6. Sampel Air Sumur Pada Perbesaran 100 kali

Pengujian menggunakan sampel dahak dapat dilakukan pada perbesaran 100, 400, dan 1000 kali. Pada

Gambar 7, Gambar 8, dan Gambar 9 merupakan hasil dari pengujian tersebut.

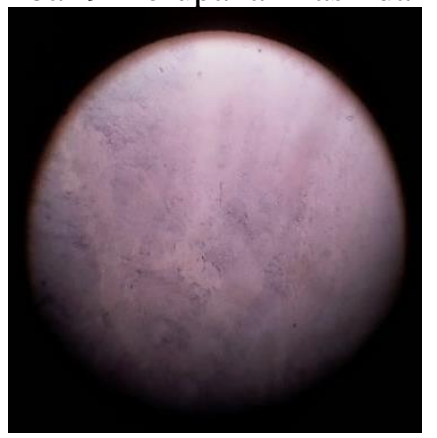

Gambar 7. Sampel Dahak Dengan Perbesaran 100 kali

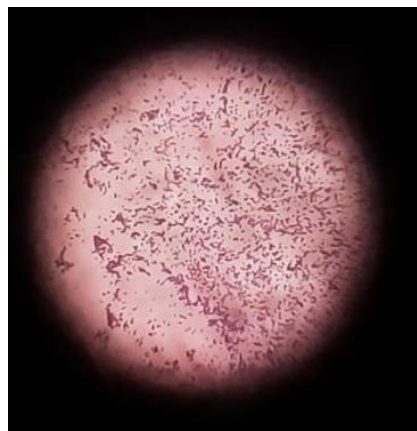

Gambar 8. Sampel Dahak Dengan Perbesaran 400 kali 


\section{Muqoddam, Kartika, Wibowo \\ Modul Digitalisasi Mikroskop}

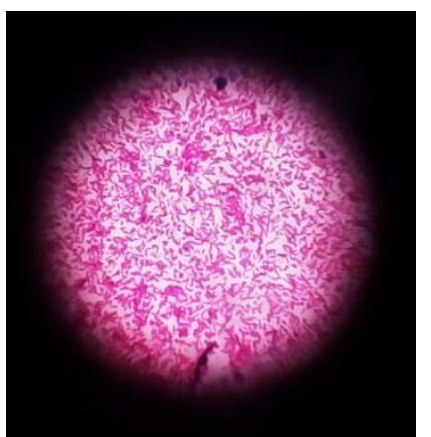

Gambar 9. Sampel Dahak Dengan Perbesaran 1000 kali

Proses pengambilan data dari sampel dahak, dilakukan di Laboratorium Rumah Sakit didampingi oleh pekerja pada Laboratorium tersebut. Hasil yang didapat menunjukan pada perbesaran 100 kali, bakteri pada sampel tersebut belum terlihat. Kemudian pada perbesaran 400 kali, bakteri pada sampel tersebut sudah terlihat tetapi belum mampu untuk dilakukan identifikasi. Pada perbesaran 1000 kali, bakteri dapat terlihat cukup jelas dan dapat dilakukan identifikasi karena ditunjukan dengan warna merah keunguan yang terdapat pada bakteri sampel dahak tersebut.

\subsection{Pengujian Survei Kinerja Modul}

Hasil kinerja dari modul digitalisasi mikroskop yang ditunjukan pada Tabel 2 ini dilakukan analisis berdasarkan sampel data yang diperoleh dari pengisian kuisioner oleh 10 responden pekerja di laboratorium Rumah Sakit Islam Klaten.

Tabel 2. Hasil Pengolahan Data Observasi Kinerja Modul Digitalisasi Mikroskop

\begin{tabular}{|l|l|l|l|l|l|l|l|l|l|l|l|l|}
\hline \multirow{2}{*}{ No } & Nama & Pekerjaan & \multicolumn{10}{|c|}{ Pernyataan } \\
\cline { 2 - 11 } & & & 1 & 2 & 3 & 4 & 5 & 6 & 7 & 8 & 9 & 10 \\
\hline 1 & HA & Laborat & 3 & 3 & 2 & 3 & 2 & 3 & 3 & 3 & 3 & 3 \\
\hline 2 & DH & Laborat & 4 & 4 & 3 & 4 & 4 & 3 & 4 & 5 & 5 & 5 \\
\hline 3 & AW & Pelaksana Lab & 4 & 4 & 4 & 4 & 2 & 4 & 4 & 4 & 5 & 5 \\
\hline 4 & WA & Pelaksana Lab & 4 & 4 & 4 & 4 & 3 & 4 & 4 & 4 & 5 & 5 \\
\hline 5 & RF & Laborat & 3 & 3 & 3 & 4 & 3 & 4 & 3 & 3 & 4 & 4 \\
\hline 6 & R & Laborat & 3 & 3 & 3 & 3 & 3 & 2 & 3 & 3 & 3 & 3 \\
\hline 7 & NA & Laborat & 4 & 4 & 3 & 4 & 4 & 3 & 3 & 4 & 4 & 4 \\
\hline 8 & DL & Laborat & 3 & 4 & 3 & 4 & 4 & 4 & 3 & 4 & 3 & 4 \\
\hline 9 & AF & Laborat & 4 & 3 & 4 & 4 & 4 & 4 & 3 & 4 & 3 & 4 \\
\hline 10 & IM & Laborat & 3 & 4 & 4 & 4 & 3 & 4 & 3 & 4 & 4 & 4 \\
\hline Total skor & & 35 & 36 & 33 & 38 & 32 & 35 & 33 & 38 & 39 & 41 \\
\hline Skor Maks : & 50 & & & & & & & & & & \\
\hline Indeks $\%$ & & 70 & 72 & 66 & 76 & 64 & 70 & 66 & 76 & 78 & 82 \\
\hline
\end{tabular}

Pada Tabel 2 didapatkan hasil data observasi dari kuisioner kinerja modul digitalisasi mikroskop yang diisi oleh 10 responden. Dari data pada Tabel 2 diperoleh jumlah total skor dari masing-masing pernyataan, kemudian dikalkulasikan untuk dihitung persentase nilai penyataan menggunakan persamaan [2-1].

Didapatkan hasil persentase nilai dengan rata-rata jangkauan $60 \%-79,99 \%$ sesuai pada Tabel 2 yang berarti seluruh responden setuju terhadap penyataan-pernyataan pada kuisioner yang diajukan.

Medika Teknika : Jurnal Teknik Elektromedik Indonesia, Vol 02 No. 1, Oktober 2020| 24 


\section{Muqoddam, Kartika, Wibowo \\ Modul Digitalisasi Mikroskop}

\subsection{Penjelasan Program}

Pada modul penelitian ini dirancang sebuah aplikasi yang digunakan untuk menampilkan hasil gambar yang ditangkap dari kamera yang kemudian gambar tersebut disimpan pada penyimpanan data. Gambar 10 merupakan tampilan awal pada saat aplikasi dijalankan.

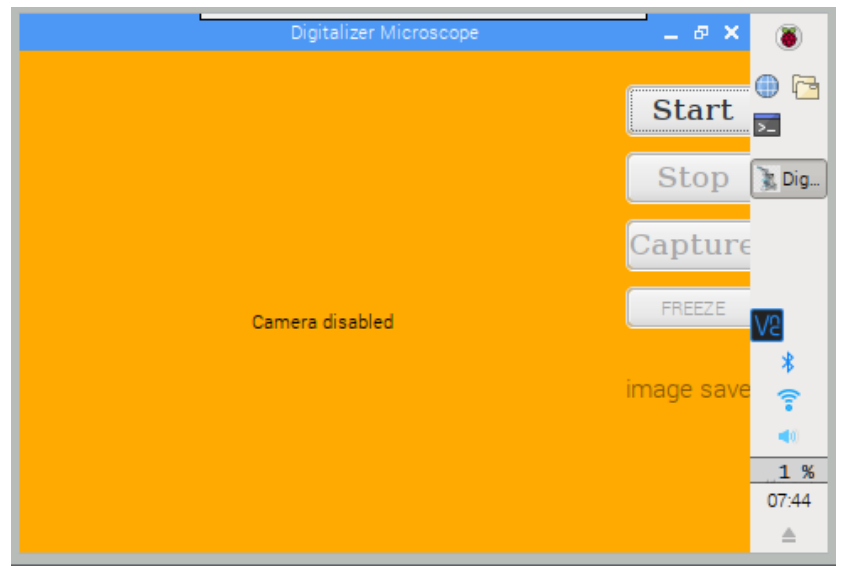

Gambar 10. Tampilan Awal Pada Aplikasi

Pada kondisi tersebut kamera belum bekerja merekam image. Ketika tombol start ditekan maka kamera akan merekam image kemudian image ditampilkan pada aplikasi tersebut seperti tampak pada Gambar 11.

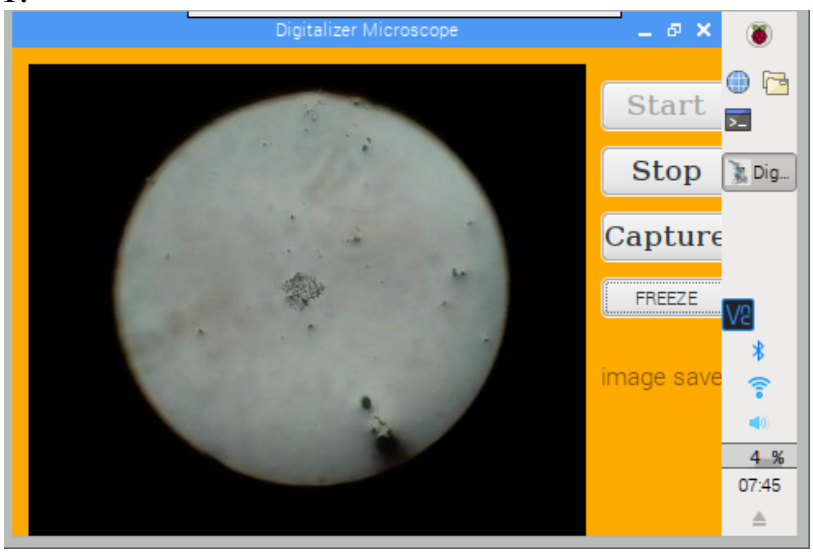

Gambar 11. Tampilan Ketika Tombol Start Ditekan

Kamera dapat merekam image karena ada sebuah perintah dari program yang dijalankan. Pada Listing Program 1 merupakan perintah agar kamera dapat merekam image. 


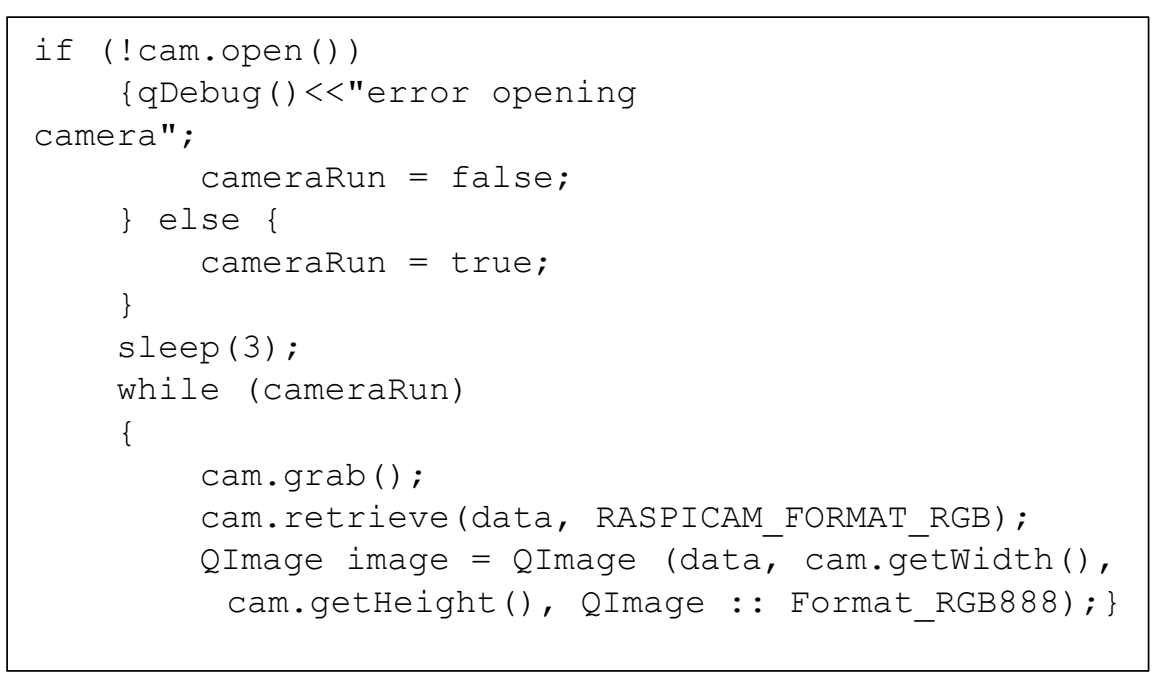

Listing Program 1. Source Code Aktivasi Kamera

Kamera akan melakukan perekaman image secara berulang karena menggunakan perintah while. Kemudian ketika image yang diinginkan telah sesuai, image dapat disimpan dengan menekan tombol capture. Pada saat tombol capture ditekan maka perintah pada Listing Program 2 dijalankan.

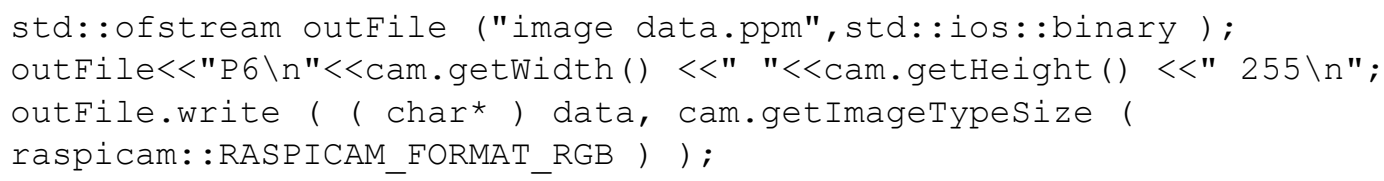

Listing Program 2. Source Code Penyimpanan Gambar (image)

\section{KESIMPULAN}

Pada pengujian menggunakan sampel (air sumur dan dahak), gambar dapat terlihat cukup jelas pada perbesaran 40, 100, 400, dan 1000 kali. Kemudian pada pengujian survei kinerja modul digitalisasi mikroskop di Laboratorium Rumah Sakit Islam Klaten menunjukkan bahwa seluruh responden setuju terhadap semua aspek penilaian kinerja dengan jangkauan rata-rata presentase sebesar $60 \%-79,99 \%$. Pada prototype modul ini juga terdapat fitur freeze yang digunakan untuk mengamati objek berupa citra (image) sebelum disimpan.

\section{DAFTAR PUSTAKA}

[1] A. Y. W. Tage., "Mikroskop digital," Surabaya, 2017.

[2] D. Wicaksono, R. R. Isnanto, and O. D. Nurhayati, "Perancangan Perangkat Lunak untuk Analisis Tingkat Fokus pada Citra Mikroskop Digital Menggunakan Proses Ekstraksi Ciri," J. Teknol. dan Sist. Komput., vol. 2, no. 1, pp. 16-22, 2014.

[3] I. Rizqa., H. Mustofa., and E. Kartikadarma., "Social Library Sebagai Salah Satu Alternatif Pelestarian Naskah Kuno," Snatif, pp. 289-294, 2016.

[4] H. Rahmi-Fajrin, S. Puspita, S. Riyadi, and E. Sofiani, "Dental radiography image enhancement for treatment evaluation through digital image processing," J. Clin. Exp. Dent., vol. 10, no. 7, pp. 0-0, 2018.

[5] S. Sastroasmoro, Dasar-dasar Metodologi Penelitian Klinis. Jakarta: SagungSeto, 2014.

[6] T. Nempung, T. Setiyaningsih, and N. Syamsiah, "Otomatisasi Metode Penelitian Skala Likert Berbasis Web," no. November, pp. 1-8, 2015. 